\title{
ESTIMATING DETECTION PROBABILITY AND SITE OCCUPANCY OF Leiolepis guentherpetersi IN THE COASTAL SANDY AREAS OF PHU LOC DISTRICT, THUA THIEN HUE PROVINCE
}

\author{
Cao Thi Thanh Nguyen, Ngo Van Binh*, Ngo Dac Chung \\ Department of Biology, Hue University of Education, Hue City, Vietnam
}

\begin{abstract}
ABTRACT
The Peter's butterfly lizard (Leiolepis guentherpetersi) is endemic to Vietnam. However, there is no available information related to detection probability and site occupancy of this species so far. Nine surveys were conducted at 50 plots in the coastal areas of Phu Loc district from September to December 2017 in order to detect the presence of Leiolepis guentherpetersi. Our results showed that the detection probability of L. guentherpetersi, when combined with environmental factors, was 0.383 , which was higher than the naive detection probability of 0.34. The total AIC weight of the near sea ecosystem was $85.9 \%$ while the total AIC weight of the ecosystem far from the sea was only $13.5 \%$. The AIC weight of weather conditions was 99.4\% while the total AIC weight of temperature was $62.3 \%$ and the total AIC weight of humidity was $27.2 \%$. These results indicated that the probability of detecting L. guentherpetersi influenced by both site covariates (near the sea or far from the sea) and sample covariates (temperature, humidity, and rainfall). In there, the near sea ecosystem is the best habitat for L. guentherpetersi and rainfall is sample covariates that had the greatest influence on detection probability and site occupancy of this species.
\end{abstract}

Keywords: Butterfly lizard, detection probability, site occupancy, Phu Loc.

Citation: Cao Thi Thanh Nguyen, Ngo Van Binh, Ngo Dac Chung, 2018. Estimating detection probability and site occupancy of Leiolepis guentherpetersi in the coastal sandy areas of Phu Loc district, Thua Thien Hue province. Academia Journal of Biology, 40(4): 37-44. https://doi.org/10.15625/26159023/v40n4.12839.

*Corresponding author email: nvb6868@gmail.com

Received 19 July 2018, accepted 5 December 2018

\section{INTRODUCTION}

The Peter's Butterfly Lizard, Leiolepis guentherpetersi Darevsky \& Kupriyanova, 1993 , is currently found in some coastal sandy areas of central Vietnam only (Nguyen et al., 2009; Grismer et al., 2014). L. guentherpetersi is a parthenogenetic species, all individuals in the population are females (Darevsky \& Kupriyanova, 1993; Grismer \& Grismer, 2010). Currently, the populations of $L$. guentherpetersi are declining at an alarming speed due to overexploitation, habitat loss, and climate change (Grismer, 2010).
Previous studies on L. guentherpetersi mainly focus on the distributed regions, morphological characters, ecology in captivity conditions, and karyotype (Darevsky \& Kupriyanova, 1993; Le \& Ngo, 2009; Nguyen et al., 2009; Tran et al., 2009; Grismer \& Grismer, 2010; Tran \& Ngo, 2012; Grismer et al., 2014). Other ecological data of L. guentherpetersi is not available. In this study, we used the dada of detection and nondetection for each plot over multiple visits to estimate the site occupancy of L. guentherpetersi in the coastal sandy areas 
of Phu Loc district, central Vietnam. We also compared detection and occupancy probabilities for two specific habitat types (site covariates) and tested the influence of sample covariates (temperature, humidity, and rainfall) on the occupancy and detection of L. guentherpetersi lizards.

\section{MATERIALS AND METHODS}

This study was carried out at the coastal sandy areas of Phu Loc district (approximately $721 \mathrm{~km}^{2}$ in size), Thua Thien Hue province, central Vietnam (Fig. 1). The study area is characterized by a monsoon tropical climate: the dry season begins from February to July and the rainy season begins from August to January next year (Nguyen et al., 2004).

We designed 50 standard plots belonging to two habitat types (site covariates) in the coastal sandy areas of Phu Loc district to monitor $L$. guentherpetersi during the rainy season of 2017. Twenty-five plots were set up close to the sea (NS) with microhabitat types represented by sandy soil, casuarinas, mangrove plants, wild pineapple, and cactus. These plots are strongly affected by the developmental projects of sea travel. Twentyfive other plots were located in the inner part of seashore from 400-1500 m (FS) with microhabitat types of mixed sandy land, acacia forests, shrubs, lawns, and bare land. Area of each standard plot is $1000 \mathrm{~m}^{2}(20 \times$ $50 \mathrm{~m}$ ). The standard plots were randomly selected, approximately $500 \mathrm{~m}$ apart from each other. We designed thirty standard plots in the Loc Vinh locality $\left(16^{\circ} 17^{\prime} 28^{\prime \prime} \mathrm{N}-\right.$ $\left.108^{\circ} 02^{\prime} 22^{\prime \prime} \mathrm{E}\right)$ with fifteen plots near the sea $(<$ $400 \mathrm{~m}$ ) and fifteen plots far from the sea (from 400-1500 m) and twenty standard plots in the Vinh Hien locality $\left(16^{\circ} 21^{\prime} 57^{\prime \prime} \mathrm{N}-\right.$ $107^{\circ} 54^{\prime} 07^{\prime \prime E}$ ) (ten plots near the sea and ten other plots far from the sea) (Fig. 1).

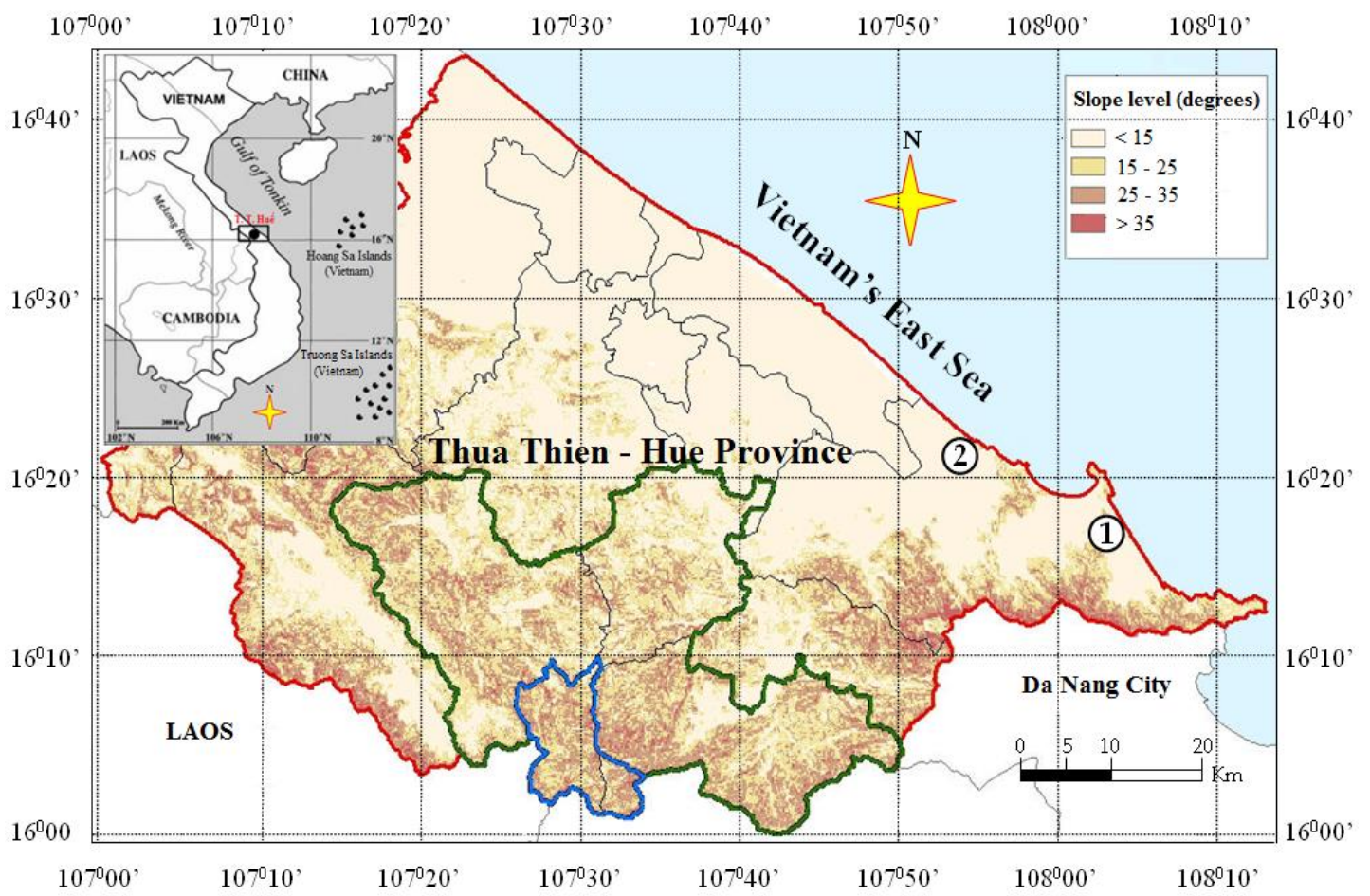

Figure 1. Map showing the study localities in the coastal sandy areas of Phu Loc district, Thua Thien Hue province: (1) Loc Vinh and (2) Vinh Hien locality 
Nine field surveys (two days for each survey) were conducted during the rainy season from September to December of 2017. All 50 plots were visited in each survey. Monitoring time lasted from 8:30 to 16:30 h. The presence of $L$. guentherpetersi was recorded in each standard plot (codes: $1=$ present, $0=$ absent). In each survey at two habitat types, we noted environmental parameters: air temperature, relative humidity, precipitation, and these factors are considered as sampling variables (sample covariates) to infer and select the best model. All statistical analyses were performed with the PRESENCE software version 12.10 (https://www.mbr-

pwrc.usgs.gov/software/presence.html).

The following parameters were tested in this study: $\psi$ is the probability of a plot where occupied by $L$. guentherpetersi; $p_{j}$ is the probability of detecting $L$. guentherpetersi in the $j^{\text {th }}$ survey.

Each plot has its own detection history that can be represented by a mathematical equation. Supposing 50 plots were each sampled four times within a season and $L$. guentherpetersi was detected at plot 1 during the first and last survey occasion (1001). The plot was occupied $(\psi)$, the probability of detecting $L$. guentherpetersi during the $j^{\text {th }}$ survey was $p_{j}$, and $L$. guentherpetersi was detected on the first and last surveys ( $p_{l}$ and $p_{4}$ ) but not on the second and third surveys. We can write the probability of this detection history as following: $\operatorname{Pr}\left(\mathrm{H}_{1}=1001\right)=\psi p_{I}(1-$ $\left.p_{2}\right)\left(1-p_{3}\right) p_{4}$.

Plot 2 represents the case where $L$. guentherpetersi was never detected (detection history $=0000$ ). This plot could either be unoccupied, which mathematically is $(1-\psi)$, or they could be occupied but not detected. In this case, we can write the probability of this detection history as follows: $\psi\left(1-p_{1}\right)(1-$ $\left.p_{2}\right)\left(1-p_{3}\right)\left(1-p_{4}\right)$ or $\psi\left(1-p_{j}\right)^{4}$. Thus, we can write the probability of detection history (0000) as follows:

$$
\operatorname{Pr}\left(\mathrm{H}_{2}=0000\right)=\psi \prod_{j=1}^{4}\left(1-p_{j}\right)+(1-\psi)
$$

Finally, the mathematical equation of all detection histories are combined into model likelihood as follows:

$$
L\left(\psi, \mathrm{p} / \mathrm{H}_{1}, \ldots, \mathrm{H}_{50}\right)=\prod_{i=1}^{50} \operatorname{Pr}\left(\mathrm{H}_{\mathrm{i}}\right)
$$

Maximum likelihood method was incorporated in the program PRESENCE version 12.10 and this software was used to obtain estimates of occupancy and detectability for $L$. guentherpetersi in the sandy coastal areas of Phu Loc district, Thua Thien Hue Province, central Vietnam. We used two essential models for the present study. The first model assumes that occupancy and detection probabilities with respect to $L$. guentherpetersi are constant across plots and surveys [denoted as $\psi() p.()$.$] .$ The second model assumes constant occupancy among plots, but detection probabilities are allowed to vary among nine surveys [denoted as $\psi()$.$p (survey)].$

We used the Akaike Information Criteria for small sample size $\left(\mathrm{AIC}_{\mathrm{c}}\right)$, usually the ratio of $n / K<40$, where $n$ is the sample size and $K$ is model parameters deduced. The difference in the Akaike Information Criteria for a particular model when compared to the topranked model $\left(\triangle \mathrm{AIC}_{\mathrm{c}}\right)$, the $\mathrm{AIC}$ model weight $(w)$, the number of parameters for each model $(K)$, and twice the negative log-likelihood value $(-2 l)$, to establish the process of model selection (Burnham \& Anderson, 2002). All models with AIC differences of $<2.0$ have a substantial level of empirical support and should be considered when making statistical inferences or reporting parameter estimates of the best models (Burnham \& Anderson, 2002). 


\section{RESULTS AND DISCUSSION}

During nine surveys, L. guentherpetersi was detected at least once at 17 of the 50 plots, yielding an overall naive occupancy estimate of 0.34 (detection probability < 1). However, testing the global model (the model with the most parameters) from the candidate set, the model [ $\psi(\mathrm{NS})$, p(temp,humid,W1,W2,W3)], when combined with environmental factors, the probability of occupying is 0.383 . The naive occupancy estimate of $L$. guentherpetersi in the Loc Vinh locality (0.4) was higher than the Vinh Hien locality $(0.3)$.

We used two basic models to test the level of statistical significance. The first model $[\psi(),. p()$.$] assumes that the occupancy and$ detection probabilities are constant across plots and surveys. The second model $[\psi(),. \mathrm{p}($ survey) $]$ assumes constant occupancy among plots, but detection probabilities are various among nine surveys (Table 1 ). The results of testing were as following: $\chi^{2}=26.04$, degree of freedom $(\mathrm{df}=8)$, significant level $(\mathrm{p}<0.001)$. This result indicated that the probability of detecting L. guentherpetersi being affected by different surveys and environmental factors. Thus, through the level of statistical significance between two basic models, we have sufficient evidence to select and infer the further models.

Table 1. Summary of two basic models to test the statistical significance of the detection probability of $L$. guentherpetersi in the coastal sandy areas of Phu Loc district. $\mathrm{AIC}_{\mathrm{c}}=$ Akaike's Information Criteria for small sample size; $\Delta \mathrm{AIC}_{\mathrm{c}}=$ the difference in AIC value for a particular model when compared with the top-ranked model; $w=$ the AIC model weight; $\mathrm{ML}=$ model likelihood; $K$ is the number of inference parameters; $-2 l$ is twice the negative log-likelihood value.

\begin{tabular}{|l|c|c|c|c|c|c|}
\hline \multicolumn{1}{|c|}{ Model } & $\mathrm{AIC}_{\mathrm{c}}$ & $\Delta \mathrm{AIC}_{\mathrm{c}}$ & $w$ & $\mathrm{ML}$ & $K$ & $-2 l$ \\
\hline$\psi(),. \mathrm{p}($ survey) & 187.78 & 0.00 & 0.993 & 1.00 & 10 & 167.78 \\
\hline$\psi(),. \mathrm{p}()$. & 197.82 & 10.04 & 0.007 & 0.01 & 2 & 193.82 \\
\hline
\end{tabular}

The results of two basic models showed that the detection probability of L. guentherpetersi in the coastal sandy areas of Phu Loc district was influenced by surveys and environmental factors. The detection probability of $L$. guentherpetersi, when combined with environmental factors (temperature, humidity, and rainfall) was 0.383 , which was higher than the naive probability (not combined with environmental factors) of 0.34 (a $12.65 \%$ increase over the plot proportion at which $L$. guentherpetersi was actually observed). The probability of detecting $L$. guentherpetersi over nine different surveys was shown in Fig. 2.

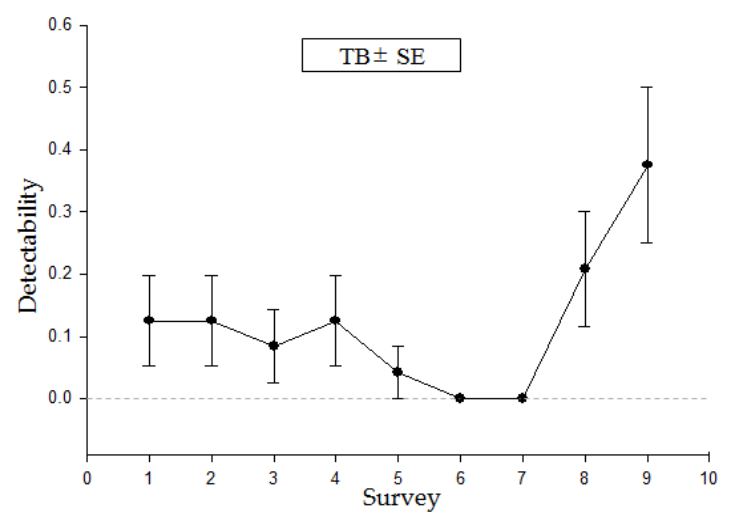

Figure 2. The probability of detecting L. guentherpetersi from the model $[\psi($.$) ,$ $\mathrm{p}$ (survey)] in this study.

Testing the model with the most parameters (seven parameters) from the candidate set (Table 2), the model [ $\psi(\mathrm{NS}), \mathrm{p}$ (temp,humid,W1,W2,W3)], does not show any evidence of overdispersion $\left(\chi^{2}=\right.$ 135.54, $\mathrm{p}=0.1287$, weighted $\hat{c}=1.13$ ), indicating insufficient evidence of the poor model fit using 10,000 bootstrap iterations. From this model with habitat types close to the sea, when combined with temperature, humidity and other weather factors (sunny, rain, and unidentified sunny-rain), the occupancy probability of $L$. guentherpetersi was 0.383; which was higher than the probability of occupying plots from the model $[\psi(),. \mathrm{p}$ (survey)] of 0.378 . 
Table 2. Summary of candidate models to infer the possible effects of environmental factors on the detection of L. guentherpetersi in the coastal sandy areas of Phu Loc district. NS = plots near the sea; FS = plots far from the sea; temp = temperature; humid = humidity; $\mathrm{W}=$ weather (including $\mathrm{W} 1$ = sunny; $\mathrm{W} 2$ = rain; $\mathrm{W} 3$ = unidentified sunny-rain)

\begin{tabular}{|c|c|c|c|c|c|c|}
\hline Model & $\mathrm{AIC}_{\mathrm{c}}$ & $\Delta \mathrm{AIC}_{\mathrm{c}}$ & $w$ & $\mathrm{ML}$ & $K$ & $-2 l$ \\
\hline$\psi(\mathrm{NS}), \mathrm{p}(\mathrm{temp}, \mathrm{W} 1, \mathrm{~W} 2, \mathrm{~W} 3)$ & 153.87 & 0.00 & 0.363 & 1.00 & 6 & 141.87 \\
\hline$\psi(\mathrm{NS}), \mathrm{p}(\mathrm{W} 1, \mathrm{~W} 2, \mathrm{~W} 3)$ & 153.87 & 0.00 & 0.359 & 1.00 & 5 & 141.87 \\
\hline$\psi(\mathrm{NS}), \mathrm{p}$ (temp, humid,W1,W2,W3) & 155.81 & 1.94 & 0.137 & 0.38 & 7 & 141.82 \\
\hline$\psi(\mathrm{FS}), \mathrm{p}($ temp, humid,W1,W2,W3) & 155.82 & 1.95 & 0.135 & 0.38 & 7 & 141.82 \\
\hline$\psi(\mathrm{NS}), \mathrm{p}$ (temp, humid) & 164.27 & 10.40 & 0.002 & 0.01 & 4 & 156.27 \\
\hline$\psi(\mathrm{FS}), \mathrm{p}$ (temp, humid) & 164.27 & 10.40 & 0.002 & 0.01 & 4 & 156.27 \\
\hline$\psi(\mathrm{FS}), \mathrm{p}$ (humid,W1,W2,W3) & 165.33 & 11.46 & 0.001 & 0.00 & 6 & 153.33 \\
\hline$\psi(\mathrm{NS}), \mathrm{p}$ (humid,W1,W2,W3) & 165.33 & 11.46 & 0.001 & 0.00 & 6 & 153.33 \\
\hline$\psi(\mathrm{FS}), \mathrm{p}$ (temp,W1,W2,W3) & 171.49 & 17.62 & 0.000 & 0.00 & 6 & 161.49 \\
\hline$\psi(\mathrm{FS}), \mathrm{p}(\mathrm{W} 1, \mathrm{~W} 2, \mathrm{~W} 3)$ & 171.49 & 17.62 & 0.000 & 0.00 & 5 & 161.49 \\
\hline$\psi(\mathrm{FS}), \mathrm{p}($ humid) & 180.51 & 26.64 & 0.000 & 0.00 & 3 & 174.51 \\
\hline$\psi(\mathrm{NS}), \mathrm{p}($ humid) & 180.51 & 26.64 & 0.000 & 0.00 & 3 & 174.51 \\
\hline$\psi(\mathrm{NS}), \mathrm{p}$ (temp) & 218.61 & 64.74 & 0.000 & 0.00 & 3 & 212.61 \\
\hline$\psi(\mathrm{FS}), \mathrm{p}$ (temp) & 218.61 & 64.74 & 0.000 & 0.00 & 3 & 212.61 \\
\hline
\end{tabular}

To evaluate the site covariates that affect the probability of detecting $L$. guentherpetersi in the coastal sandy areas of Phu Loc district, based on the influence of AIC weight on $\Delta \mathrm{AIC} \leq 2.0$; the total $\mathrm{AIC}$ weight $\mathrm{NS}=0.859$, accounting for $85.9 \%$; the total AIC weight $\mathrm{FS}=0.135$, accounting for $13.5 \%$ (evidence ratio [Akaike weight of the $\psi(\mathrm{NS})$ model/Aikaike weight of the $\psi(\mathrm{FS})$ model $=$ 6.36 times). This indicated that habitat types near the sea were strong determinants of L. guentherpetersi occupancy and the near sea ecosystem was the best habitat for this species.

In addition, the detection probability of L. guentherpetersi also being influenced by the sample covariates such as temperature, humidity, rainfall, and even surveys. Our results showed that the total AIC weight temp $=0.623$; the total AIC weight humid $=0.272$; the total AIC weight $\mathrm{W}=0.994$. From these results indicated that environmental factors affected the detection probability of
L. guentherpetersi. However, weather conditions were the most important factor for the detection probability of $L$. guentherpetersi compared to temperature and humidity factors. To determine the influence of each weather factor (sunny, rain, and unidentified weather) for the detection probability of L. guentherpetersi, we used the candidate models as presented in table 3 .

Weather conditions had a great effect on the detection probability of L. guentherpetersi. In there, the total AIC weight $\mathrm{W} 1=0.418$; the total AIC weight W2 $=0.582$; the total AIC weight $\mathrm{W} 3=1.0$. As a result, the detection probability of $L$. guentherpetersi being influenced by site covariates (near the sea or far from the sea) and sample covariates (temperature, humidity, and rainfall). In there, weather conditions had a direct and significant impact on the detection probability of L. guentherpetersi and the unidentified weather factor (W3) still had the greatest influence. 
Cao Thi Thanh Nguyen et al.

Table 3. Summary of candidate models to infer the effect of sunny, rain, and unidentified sunnyrain factors on the detection probability of $L$. guentherpetersi in the coastal sandy areas of Phu Loc district

\begin{tabular}{|c|c|c|c|c|c|c|}
\hline Model & $\mathrm{AIC}_{\mathrm{c}}$ & $\Delta \mathrm{AIC}_{\mathrm{c}}$ & $w$ & $\mathrm{ML}$ & $K$ & $-2 l$ \\
\hline$\psi(\mathrm{NS}), \mathrm{p}(\mathrm{W} 2, \mathrm{~W} 3)$ & 195.76 & 0.00 & 0.395 & 1.00 & 4 & 187.76 \\
\hline$\psi(\mathrm{NS}), \mathrm{p}(\mathrm{W} 1, \mathrm{~W} 3)$ & 195.76 & 0.00 & 0.229 & 1.00 & 4 & 187.76 \\
\hline$\psi(\mathrm{FS}), \mathrm{p}(\mathrm{W} 1, \mathrm{~W} 3)$ & 196.77 & 1.01 & 0.189 & 0.62 & 4 & 188.77 \\
\hline$\psi(\mathrm{FS}), \mathrm{p}(\mathrm{W} 2, \mathrm{~W} 3)$ & 196.77 & 1.01 & 0.187 & 0.61 & 4 & 188.77 \\
\hline$\psi(\mathrm{NS}), \mathrm{p}(\mathrm{W} 3)$ & 216.35 & 20.59 & 0.000 & 0.00 & 3 & 210.35 \\
\hline$\psi(\mathrm{FS}), \mathrm{p}(\mathrm{W} 3)$ & 216.35 & 20.59 & 0.000 & 0.00 & 3 & 210.35 \\
\hline$\psi(\mathrm{NS}), \mathrm{p}(\mathrm{W} 1, \mathrm{~W} 2)$ & 237.55 & 41.79 & 0.000 & 0.00 & 4 & 229.55 \\
\hline$\psi(\mathrm{FS}), \mathrm{p}(\mathrm{W} 1, \mathrm{~W} 2)$ & 237.55 & 41.79 & 0.000 & 0.00 & 4 & 229.55 \\
\hline$\psi(\mathrm{NS}), \mathrm{p}(\mathrm{W} 2)$ & 255.41 & 59.64 & 0.000 & 0.00 & 3 & 249.41 \\
\hline$\psi(\mathrm{FS}), \mathrm{p}(\mathrm{W} 2)$ & 255.41 & 59.64 & 0.000 & 0.00 & 3 & 249.41 \\
\hline$\psi(\mathrm{FS}), \mathrm{p}(\mathrm{W} 1)$ & 258.49 & 62.73 & 0.000 & 0.00 & 3 & 252.49 \\
\hline$\psi(\mathrm{NS}), \mathrm{p}(\mathrm{W} 1)$ & 258.49 & 62.73 & 0.000 & 0.00 & 3 & 252.49 \\
\hline
\end{tabular}

Note: symbols and abbreviated words in this table like table 2

\section{CONCLUSION}

The detection probability of L. guentherpetersi, when combined with environmental factors, was 0.383 , which was higher than the probability of naive detection (only 0.34 ). The extinct probability of this species in the study area was very high (about $62.2 \%)$.

The detection probability of L. guentherpetersi being affected by the site covariates (evidence ratio of Akaike weight $=$ 6.36 times). In there, the near sea ecosystem was the best habitat for this species.

The detection probability of L. guentherpetersi also being influenced by sample covariates (temperature, humidity, and rainfall). In there, the unidentified weather factor had the greatest influence.

Acknowledgements: This research was supported by the Department of Biology, Hue University of Education. We thank Huynh Thi Tuong Vy, Nguyen Tan Long, Dong Thi Suong, Ho Thi My Quy and Tran Thi Kim Anh for our assistance during the study period.

\section{REFERENCES}

Burnham K. P., Anderson D. R., 2002. Model Selection and Inference: a Practical
Information-theoretic Approach. SpringerVerlag, New York, USA, 488 pp.

Darevsky I. S., Kupriyanova L. A., 1993. Two new all-female lizard species of the genus Leiolepis Cuvier, 1829 from Thailand and Vietnam (Squamata: Sauria: Uromastycinae). Herpetozoa, 6(1/2): 3-20.

Grismer J. L., 2010. Phylogeny, Taxonomy, Biogeography and Evolution of Asexuality within the Southeast Asian Lizard Genus Leiolepis Cuvier (1829). A Thesis Presented to the Department of Biology, Villanova University, USA.

Grismer J. L., Bauer A. M., Grismer L. L., Thirakhupt K., Aowphol A., Oaks J. R., Wood P. L., Onn C. K., Thy N., Cota M., Jackman T., 2014. Multiple origins of parthenogenesis, and a revised species phylogeny for the Southeast Asian butterfly lizards, Leiolepis. Biol. J. Linn. Soc., 113: 1080-1093.

Grismer J. L., Grismer L. L., 2010. Who's your mommy? Identifying maternal ancestors of asexual species of Leiolepis Cuvier, 1829 and the description of a new endemic species of asexual Leiolepis Cuvier, 1829 from Southern Vietnam. Zootaxa, 2433: 47-61. 
Le N. T., Ngo C. D., 2009. Some population characteristics of the Butterfly Lizard Leiolepis reevesii (Gray, 1861) and Leiolepis guentherpetersi in Da Nang. Proceedings in the $1^{\text {st }}$ National Scientific Workshop on Amphibians and Reptiles in Vietnam". Hue University Press, Hue, Vietnam, pp. 233-244.

Nguyen V., Truong D. H., Hoang T. L., et al., 2004. Climatic-hydrology characters of Thua Thien Hue province. Thuan Hoa Publishing House, Hue, Vietnam.

Nguyen V. S., Ho T. C., Nguyen Q. T., 2009. Herpetofauna of Vietnam. Edition Chimaira. Frankfurt am Main, Germany, $767 \mathrm{pp}$.
Tran D. Q., Ngo C. D., Tran T. V., 2009. Comparative analysis of the karyotypes of two Agamidae species of the genus Leiolepis in Thua Thien Hue province. Proceedings in the $1^{\text {st }}$ National Scientific Workshop on Amphibians and Reptiles in Vietnam". Hue University Press, Hue, Vietnam, pp. 39-42.

Tran D. Q., Ngo T. Q., 2012. Data on nutrition and growth of the Butterfly Lizards Leiolepis guentherpetersi (Darevsky and Kupriyanova, 1993) in raising condition in Hue city. Proceedings in the $2^{\text {nd }}$ National Scientific Workshop on Amphibians and Reptiles in Vietnam. Vinh University Press, Nghe An, pp. 120-136.

Appendix A. The data of detection history for Leiolepis guentherpetersi during the the rainy season in the coastal sandy areas of Phu Loc district, Thua Thien Hue province

\begin{tabular}{|c|c|c|c|c|c|c|c|c|c|c|c|}
\hline \multirow{2}{*}{ Plots } & \multirow{2}{*}{ NS } & \multirow{2}{*}{ FS } & \multicolumn{9}{|c|}{ Surveys } \\
\cline { 5 - 12 } & & & I & II & III & IV & V & VI & VII & VII & IX \\
\hline 1 & 0 & 1 & 0 & 0 & 0 & 0 & 0 & 0 & 0 & 0 & 0 \\
\hline 2 & 0 & 1 & 0 & 0 & 0 & 0 & 0 & 0 & 0 & 0 & 0 \\
\hline 3 & 0 & 1 & 0 & 0 & 0 & 0 & 0 & 0 & 0 & 0 & 0 \\
\hline 4 & 0 & 1 & 0 & 0 & 0 & 0 & 0 & 0 & 0 & 0 & 0 \\
\hline 5 & 0 & 1 & 0 & 0 & 0 & 0 & 0 & 0 & 0 & 0 & 0 \\
\hline 6 & 0 & 1 & 0 & 0 & 0 & 0 & 0 & 0 & 0 & 0 & 0 \\
\hline 7 & 0 & 1 & 0 & 0 & 0 & 0 & 0 & 0 & 0 & 0 & 1 \\
\hline 8 & 0 & 1 & 0 & 0 & 0 & 0 & 0 & 0 & 0 & 0 & 0 \\
\hline 9 & 0 & 1 & 0 & 0 & 0 & 0 & 0 & 0 & 0 & 0 & 0 \\
\hline 10 & 0 & 1 & 0 & 0 & 0 & 0 & 0 & 0 & 0 & 0 & 0 \\
\hline 11 & 0 & 1 & 0 & 0 & 0 & 0 & 0 & 0 & 0 & 1 & 0 \\
\hline 12 & 0 & 1 & 0 & 0 & 0 & 0 & 0 & 0 & 0 & 0 & 0 \\
\hline 13 & 0 & 1 & 0 & 0 & 0 & 0 & 0 & 0 & 0 & 0 & 0 \\
\hline 14 & 0 & 1 & 0 & 0 & 0 & 0 & 0 & 0 & 0 & 0 & 1 \\
\hline 15 & 0 & 1 & 0 & 0 & 0 & 0 & 0 & 0 & 0 & 0 & 0 \\
\hline 16 & 1 & 0 & 0 & 0 & 0 & 0 & 0 & 0 & 0 & 0 & 0 \\
\hline 17 & 1 & 0 & 0 & 0 & 0 & 0 & 0 & 0 & 0 & 0 & 0 \\
\hline 18 & 1 & 0 & 0 & 0 & 1 & 0 & 0 & 0 & 0 & 1 & 1 \\
\hline 19 & 1 & 0 & 1 & 0 & 0 & 0 & 0 & 0 & 0 & 0 & 1 \\
\hline 20 & 1 & 0 & 0 & 0 & 0 & 0 & 0 & 0 & 0 & 0 & 1 \\
\hline 21 & 1 & 0 & 0 & 0 & 0 & 0 & 0 & 0 & 0 & 0 & 0 \\
\hline 22 & 1 & 0 & 0 & 0 & 0 & 0 & 0 & 0 & 0 & 0 & 0 \\
\hline 23 & 1 & 0 & 0 & 0 & 0 & 0 & 0 & 0 & 0 & 0 & 0 \\
\hline 24 & 1 & 0 & 0 & 0 & 0 & 0 & 0 & 0 & 0 & 0 & 0 \\
\hline 25 & 1 & 0 & 0 & 0 & 0 & 0 & 0 & 0 & 0 & 0 & 0 \\
\hline 26 & 1 & 0 & 0 & 0 & 0 & 0 & 0 & 0 & 0 & 0 & 1 \\
\hline
\end{tabular}


Cao Thi Thanh Nguyen et al.

\begin{tabular}{|c|c|c|c|c|c|c|c|c|c|c|c|}
\hline \multirow{2}{*}{ Plots } & \multirow{2}{*}{ NS } & \multirow{2}{*}{ FS } & \multicolumn{9}{|c|}{ Surveys } \\
\cline { 3 - 13 } & & & I & II & III & IV & V & VI & VII & VII & IX \\
\hline 27 & 1 & 0 & 1 & 0 & 0 & 1 & 0 & 0 & 0 & 0 & 0 \\
\hline 28 & 1 & 0 & 0 & 0 & 0 & 1 & 0 & 0 & 0 & 1 & 0 \\
\hline 29 & 1 & 0 & 0 & 0 & 1 & 1 & 0 & 0 & 0 & 0 & 0 \\
\hline 30 & 1 & 0 & 1 & 0 & 0 & 0 & 0 & 0 & 0 & 0 & 0 \\
\hline 31 & 1 & 0 & 0 & 0 & 0 & 0 & 0 & 0 & 0 & 0 & 0 \\
\hline 32 & 1 & 0 & 0 & 0 & 0 & 0 & 0 & 0 & 0 & 0 & 1 \\
\hline 33 & 1 & 0 & 0 & 0 & 0 & 0 & 0 & 0 & 0 & 0 & 0 \\
\hline 34 & 1 & 0 & 0 & 0 & 0 & 0 & 0 & 0 & 0 & 0 & 0 \\
\hline 35 & 1 & 0 & 0 & 0 & 0 & 0 & 0 & 0 & 0 & 0 & 0 \\
\hline 36 & 1 & 0 & 0 & 0 & 0 & 0 & 0 & 0 & 0 & 0 & 0 \\
\hline 37 & 1 & 0 & 0 & 1 & 0 & 0 & 0 & 0 & 0 & 1 & 0 \\
\hline 38 & 1 & 0 & 0 & 0 & 0 & 0 & 0 & 0 & 0 & 0 & 0 \\
\hline 39 & 1 & 0 & 0 & 1 & 0 & 0 & 1 & 0 & 0 & 0 & 1 \\
\hline 40 & 1 & 0 & 0 & 1 & 0 & 0 & 0 & 0 & 0 & 0 & 0 \\
\hline 41 & 0 & 1 & 0 & 0 & 0 & 0 & 0 & 0 & 0 & 0 & 1 \\
\hline 42 & 0 & 1 & 0 & 0 & 0 & 0 & 0 & 0 & 0 & 0 & 0 \\
\hline 43 & 0 & 1 & 0 & 0 & 0 & 0 & 0 & 0 & 0 & 1 & 0 \\
\hline 44 & 0 & 1 & 0 & 0 & 0 & 0 & 0 & 0 & 0 & 0 & 0 \\
\hline 45 & 0 & 1 & 0 & 0 & 0 & 0 & 0 & 0 & 0 & 0 & 0 \\
\hline 46 & 0 & 1 & 0 & 0 & 0 & 0 & 0 & 0 & 0 & 0 & 0 \\
\hline 47 & 0 & 1 & 0 & 0 & 0 & 0 & 0 & 0 & 0 & 0 & 0 \\
\hline 48 & 0 & 1 & 0 & 0 & 0 & 0 & 0 & 0 & 0 & 0 & 0 \\
\hline 49 & 0 & 1 & 0 & 0 & 0 & 0 & 0 & 0 & 0 & 0 & 0 \\
\hline 50 & 0 & 1 & 0 & 0 & 0 & 0 & 0 & 0 & 0 & 0 & 0 \\
\hline
\end{tabular}

